\title{
A INSUSTENTABILIDADE SOCIAL E AMBIENTAL DO AGRONEGÓCIO: A TERRITORIALIZAÇÃO DO COMPLEXO CELULOSE-PAPEL NA REGIÃO LESTE DE MATO GROSSO DO SUL
}

Rodrigo Simão Camacho ${ }^{1}$

Resumo: Este artigo está relacionado com o projeto aprovado pelo CNPq que tem como título: "A formação do vale da celulose: desdobramentos socioterritoriais do plantio de eucalipto na região Leste de Mato Grosso do Sul". O objetivo do artigo é discutir a insustentabilidade do agronegócio, mais especificamente, do setor de celulose-papel. O agronegócio, pelas suas características principais: a concentração de terra e renda, a monocultura, o uso intensivo de agrotóxicos, a mecanização, a produção de commodities, exploração intensa da mão de obra, o uso de transgênicos etc. mostra-se um modelo insustentável. As características predatórias do agronegócio são encontradas na territorialização do eucalipto na região leste de Mato Grosso do Sul.

Palavras-chave: Agronegócio. Eucalipto. Insustentabilidade.

\section{INTRODUÇÃO}

Este artigo está relacionado com o projeto aprovado pelo $\mathrm{CNPq}^{2}$ que tem como título: "A formação do vale da celulose: desdobramentos socioterritoriais do plantio de

\footnotetext{
${ }^{1}$ Doutorando em Geografia pela FCT/UNESP - Presidente Prudente/SP. Membro do Grupo de pesquisa NERA. Bolsista Fapesp. Email: rogeo@ymail.com.
} 
eucalipto na região Leste de Mato Grosso do Sul", tendo em vista que no projeto está mencionado que a publicização do trabalho se dará com produção de textos expandidos a serem apresentados em eventos regionais, nacionais e internacionais e artigos a serem submetidos a periódicos indexados, nacionais e estrangeiros.

$\mathrm{Na}$ primeira parte do artigo, apresentamos um debate acerca de nossa perspectiva teórica-política-ideológica sobre 0 agronegócio e seus impactos socioambientais. O agronegócio, pelas suas características principais: a concentração de terra e renda, a monocultura, o uso intensivo de agrotóxicos, a mecanização, a produção de commodities, exploração intensa da mão de obra, o uso de transgênicos etc. mostrase um modelo insustentável. Na segunda parte do artigo, discutimos a expansão do complexo celulose-papel na região leste de Mato Grosso do Sul e seus impactos sociais e biofísicos. Mostramos que as características predatórias, características do agronegócio, são encontradas na territorialização do eucalipto nesta região. Entre os impactos causados na região de Três Lagoas podemos citar: a mudança no balanço hídrico que levou a eliminação de nascentes; mudanças nos hábitos da fauna que levou a alguns animais invadir propriedades em busca de comida; os riscos à saúde na qual estão expostos os camponeses-assentados que estão cercados pelo eucalipto e podem ser contaminados pelo glifosato; a perda da biodiversidade do cerrado pelo agroecossistema simplificado do eucalipto e pelo uso de agrotóxicos; a paisagem degradada após a colheita mecanizada do eucalipto; o desrespeito à legislação ambiental na derrubada e envenenamento de árvores nativas; a apropriação predatória dos recursos hídricos disponíveis para o plantio e para a produção da celulose, no caso a bacia do Rio Paraná e o aquífero Caiuá-Bauru;

\section{1-O AGRONEGÓCIO E SUA INSUSTENTABILIDADE SOCIAL E BIOFÍSICA}

Impacto ambiental é o processo de mudanças sociais e ecológicas causado por perturbações (uma nova ocupação e/o construção de um objeto novo: uma usina, uma estrada ou uma indústria) no ambiente. [...] Impacto ambiental é indivisível. [...] torna-se cada vez mais difícil separar impacto biofísico de impacto social. $\mathrm{Na}$ produção dos impactos ambientais, as condições ecológicas alteram as condições culturais, sociais e históricas, e são por elas transformadas. Como um

\footnotetext{
${ }^{2}$ A coordenadora do projeto é a Prof $\stackrel{\text { a }}{ }$. Dra . Rosemeire A. de Almeida. Eu sou um dos colaboradores do Projeto.
} 
processo e movimento permanente, o impacto ambiental é, ao mesmo tempo, produto e produtor de novos impactos. (COELHO, 2001, p.24-25, grifo nosso).

O conceito de agronegócio, na língua portuguesa, que deriva da palavra agribusiness, foi cunhado em 1957 por Davis e Goldberg e significa um complexo de sistemas que integra todas as dimensões da economia capitalista: agricultura indústria - comércio - finanças. Esses sistemas estão sob o controle das transnacionais (FERNANDES, 2008).

Conforme explica João Pedro Stedile (2006), apesar de a palavra agronegócio significar qualquer operação comercial de produtos agrícolas, no Brasil esse conceito ganhou uma nova significação, está relacionado com a implantação de um modelo de produção agrícola que é fruto de uma aliança com o capital agropecuário internacional representado pela Associação Brasileira de Agribusiness. Seu fundador foi um grande produtor de cana, laranja e soja chamado Roberto Rodrigues. Houve uma aliança subordinada dos latifundiários, com os capitalistas exportadores e as empresas transnacionais que controlam o mercado agrícola mundial, as sementes, a produção de agrotóxicos e a agroindústria. O resultado dessa fusão é o agronegócio. Nesse complexo de sistemas globalizados temos dez empresas transnacionais que controlam todo 0 mercado do setor de agronegócio. Estas empresas são: Monsanto, Bunge, Cargil, ADM, Basf, Bayer, Sygenta, Novartis, Nestlé e Danone. Estas empresas controlam a produção agrícola, de agrotóxicos e de sementes transgênicas, e o comércio agrícola de exportação.

A estrutura desse modelo agrário-agrícola nacional é a aliança entre o capital nacional e o capital internacional: capitalistas proprietários de terra, o capital financeiro internacional, capital industrial, sobretudo agroquímico, e o capital comercial.

[...] (1) as grandes corporações financeiras internacionais; (2) as grandes indústrias-laboratórios de adubos e de fertilizantes, de herbicidas e de sementes; (3) as grandes cadeias de comercialização ligadas aos supermercados e farmácias; e (4) os grandes latifúndios exportadores de grãos. [...]. (PORTOGONÇALVES, 2004, p. 227, grifo do autor).

Com essas características descritas acerca do agronegócio, os impactos sociais causados por este modelo de produção agrícola são notáveis na sociedade brasileira. $O$ primeiro diz respeito ao aumento da concentração fundiária. Corroborando nesta 
análise, João Pedro Stedile afirma que: "[...] a concentração da propriedade da terra continuou aumentando. Eles acumularam nestes últimos anos mais de 30 milhões de hectares, somente nas fazendas acima de 1.000 hectares [...]". (2006, p.17).

O Brasil é o quinto país do mundo em extensão territorial, portanto, o problema de acesso a terra não era para existir dentro do território brasileiro. Mas, concluímos, analisando a nossa estrutura fundiária via dados oficiais do INCRA, que temos uma intensa concentração fundiária no Brasil. De nossa área territorial total de 850,2 milhões de hectares, temos 170,0 milhões de terras devolutas. Estas terras são públicas, pertencem ao Estado e a União e devem ser utilizadas para a reforma agrária segundo a nossa constituição. O problema é que estas terras estão ocupadas ilegalmente. Isto significa que existem latifundiários com propriedades maiores do que seus títulos alegam oficialmente (OLIVEIRA, 2003). Esta privatização ilegal de terras públicas compreende ao que denominamos de Grilagem. Esta é uma denominação utilizada para se referir a terras apossadas de terceiros de maneira fraudulenta ou pela força (ALMEIDA, 2004).

A busca por parte do agronegócio de terras planas, férteis e com disponibilidade hídrica, terras que possam ter a sua produção mecanizada, estão causando conflitos territoriais (THOMAZ JUNIOR, 2010). Estas disputas tem deflagrado uma questão de suma importância que diz respeito à violência no campo, ou seja, existe uma relação entre a territorialização do capital no campo e o aumento da violência, inclusive com assassinatos de lideranças dos movimentos sociais camponeses, o que confirma a barbárie do agronegócio e sua natureza moderna-colonial (PORTO-GONÇALVES, 2004).

Outro fator de impactos ligados ao agronegócio é que, ao contrário do que se pensa, o uso das sementes transgênicas não está diretamente associado ao aumento da produtividade, mas sim, a diminuição de custos com mão-de-obra devido à possibilidade de não precisar combater as pragas e as facilidades de semeadura. $O$ resultado disso é a produção de uma "agricultura sem agricultores", pois se necessita de menos empregos no campo, elevando-se o êxodo rural. Assim, os transgênicos, além de ser uma forma degradante ambientalmente de produção, porque gera a erosão genética, também acarreta o desemprego no campo (PORTO-GONÇALVES, 2004).

Com relação à constituição da cultura no campo, para Carlos Walter PortoGonçalves, os sujeitos ao produzirem a agricultura, concomitantemente, criam cultura a 
partir das relações espaciais e históricas estabelecidas nesse processo. Todavia, no agronegócio a produção agrícola não está relacionada à produção da cultura. Este fato faz desses territórios, onde o capital se territorializou, o local da expropriação camponesa, de trabalhadores assalariados (poucos) e de muitas máquinas e, assim, "[...] não só se perde diversidade biológica, mas também a diversidade cultural e múltiplas formas de propriedade distintas da propriedade privada [...]". (PORTO-GONÇALVES, 2004, p.224, grifo nosso).

Faz-se necessário mencionarmos que as destruições causadas pelo agronegócio são sociais e ambientais. Isto porque existe um conjunto de elementos presentes neste modelo que são fortemente degradantes. A monocultura, característica do agronegócio, fragiliza a biodiversidade, colaborando no aumento de pragas, devido à homogeneização do ecossistema. O uso de agrotóxicos polui o solo e a água destruindo a nossa biodiversidade. O agronegócio organiza seu território apenas a partir da lógica econômica da mercadoria, por isso predomina a paisagem homogênea da monocultura, com seus agroecossistemas simplificados, com poucas pessoas e com pouca sociobiodiversidade. Ao contrário dos territórios povoados e das paisagens heterogêneas da agricultura camponesa que contemplam a sociobiodiversidade e os agroecossistemas complexos (PORTO GONÇALVES, 2004; FERNANDES, 2008; CAMACHO, 2008).

De acordo com Carlos Walter Porto-Gonçalves (2004), os agroecossistemas criados pelo agronegócio comprometem a biodiversidade, pois a monocultura simplifica ao extremo as relações naturais existentes, necessitando de uma grande quantidade de insumos externos, como adubos e agrotóxicos para que a produção possa acontecer. Pois, a dependência de alguns poucos cultivadores, torna esses agroecossistemas vulneráveis a pragas e às variações climáticas. Essa relação se torna ainda mais delicada quando verificamos que esses agroecossistemas estão sendo implantados no Brasil e no restante dos países tropicais tendo como base uma racionalidade científica européia, cujo clima é temperado e não o tropical. Por isso, necessitaríamos de outra racionalidade técnica-científica para produção em países tropicais, pois nesses lugares os impactos se tornam mais violentos que nos países de clima temperado que tem uma menor quantidade de energia solar envolvida no processo e onde a diversidade biológica 
é menos intensa. É necessário sabermos que a implantação dos agroecossistemas simplificados não responde da mesma forma em biomas distintos. Todavia, nossa ciência eurocêntrica tenta, ideologicamente, homogeneizar esses ecossistemas por interesses de exploração da nossa biodiversidade, reduzindo a complexidade desses sistemas naturais tropicais.

Devido à fragilidade desses agroecossistemas se faz necessário o uso cada vez maior de insumos agroquímicos. É notável como vem aumentando a quantidade do uso desses insumos ao longo do tempo. Esse aumento é alvo de críticas por parte de entidades preocupadas com o bem-estar das pessoas e do meio-ambiente no campo. Segundo Carlos Walter Porto-Gonçalves: "[...] Nos últimos cinquenta anos, enquanto a produção de grãos aumentou três vezes, o uso de fertilizantes foi multiplicado simplesmente catorze vezes, segundo dados da FAO [...]". (2004, p.225). O emprego desses insumos tem como consequência a poluição dos rios e dos solos, causando a morte de peixes e comprometendo a reprodução das comunidades ribeirinhas que tem na pesca uma atividade principal ou complementar de sua subsistência. Outro fator relevante é que esses insumos agroquímicos não ofendem somente a natureza, mas atingem diretamente a saúde dos moradores e/ou trabalhadores do campo. O desfolhante químico conhecido como "agente laranja" foi usado em novembro de 2002 no preparo da terra para a plantação de grãos na região norte conhecida como "Bico do Papagaio", entre o Maranhão e o Tocantins. Esse produto foi usado pelos EUA na guerra do Vietnã e até hoje seus efeitos estão presentes na população do país (PORTOGONÇALVES, 2004).

O MST, a Via Campesina Brasil, junto com outras entidades, lançaram a campanha em 2011 intitulada: Agrotóxico Mata: campanha permanente contra os agrotóxicos e pela vida. A fim de alertar a população acerca dos perigos dos agrotóxicos para a saúde humana e para o meio ambiente, bem como dos abusos de que o agronegócio faz do mesmo. Somos o país que mais usa agrotóxicos no mundo, sendo que cada brasileiro consome cerca de 5,2 litros de venenos por ano. Vejamos o que diz a campanha: 
de venenos foram jogados nas lavouras, de acordo com dados oficiais. Os agrotóxicos contaminam a produção dos alimentos que comemos e a água (dos rios, lagos, chuvas e os lençóis freáticos) que bebemos! Mas os venenos não estão só no nosso prato. Todos, o ambiente, os animais e nós, seres humanos, estamos ameaçados! Os agrotóxicos causam uma série de doenças muito sérias, que atacam os trabalhadores rurais, comunidades rurais e toda a população, que consome alimentos com substâncias tóxicas e adquire muitas doenças. (grifo nosso).

O capitalismo segue sua lógica perversa no campo, tendo como características essenciais: exploração da natureza combinada com a exploração das pessoas. A territorialização do capital no campo só é possível porque tem à sua disposição elementos imprescindíveis para a sua expansão. O agronegócio tem favorecimento dos investimentos públicos e privados e tem acesso às melhores terras: planas, férteis, localização favorável e logística de transportes adequada. Outro elemento imprescindível é o acesso à água, tanto superficial: grandes rios, reservatórios de hidrelétricas, lagos, quanto subterrânea, sobretudo, os aquíferos Caiuá-Bauru e Serra Geral, no Centro-Sul do País. Estas regiões contam com índices pluviométricos regulares de proporção adequada às necessidades de reprodução das monoculturas do agronegócio: cana-de-açúcar, soja, eucalipto, laranja etc. (THOMAZ JUNIOR, 2010).

Com relação à exploração da natureza é relevante ressaltarmos que o agronegócio tem se territorializado em regiões de fácil acesso a água. Esta forma de expansão territorial, por parte da agroindústria exportadora capitalista, que invade territórios dotados de abundância de água, é o que Antonio Thomaz Junior tem denominado de agrohidronegócio. Grande parte da produção do agronegócio, cana-deaçúcar, soja e eucalipto, estão localizados no polígono do agrohidronegócio (Mapa 01).

A expansão da agropecuária capitalista, no Brasil, referenciada no modelo agroexportador, se consolida territorialmente no que denominamos de Polígono do Agrohidronegócio, a contar com o Oeste de São Paulo, Leste do Mato Grosso do Sul, Noroeste do Paraná, Triângulo Mineiro e Sul-Sudoeste de Goiás. Está-se diante de $80 \%$ das plantações de cana-de-açúcar, também de concentração das plantas agroprocessadoras, de produção de álcool e de açúcar do país, bem como $30 \%$ das terras com soja e onde se registra os maiores avanços em termos de área com plantações de eucaliptos. [...]. (2010, p. 91, grifo nosso). 

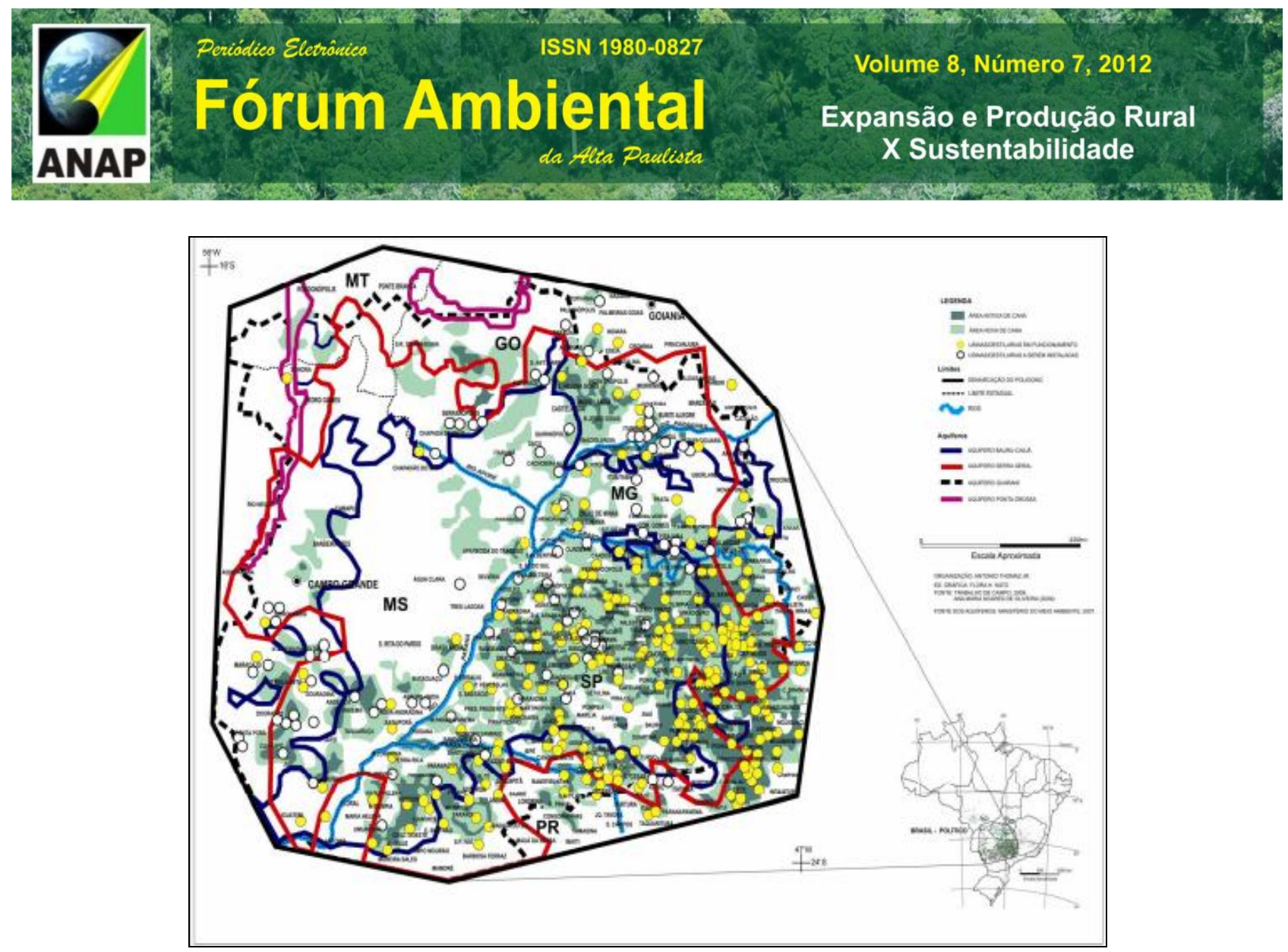

Mapa 01 - Polígono do Agrohidronegócio no Brasil.

Fonte: THOMAZ JUNIOR, Antonio (2010).

A apropriação da água por parte do agronegócio faz com que possamos afirmar que estamos exportando junto com as commodities grande quantidade de água. Estimase que $67 \%$ da água virtual que circula está relacionada com a exportação de grãos dentre outras commodities. O Brasil é o décimo exportador líquido de água virtual, o que significa um custo ecológico não considerado em nossa economia (CAPORAL, 2009).

\section{2- OS IMPACTOS SOCIAIS E AMBIENTAIS CAUSADOS PELA TERRITORIALIZAÇÃO DO EUCALIPTO NA REGIÃO LESTE DE MATO GROSSO DO SUL}

O Brasil é o país que possui a maior superfície mundial de área plantada com eucalipto. Vejamos o que diz Sérgio Schlesinger acerca destes dados:

As florestas artificiais ocupam atualmente, no Brasil, a quarta posição em termos de área cultivada, atrás da soja, do milho e da cana-de-açúcar. [...]. O País possui a maior superfície mundial de área plantada com eucalipto. A maior parte das florestas artificiais - cerca de 30\% - destina-se à produção de papel e celulose. (SCHLESINGER, 2008, p. 61, grifo nosso). 


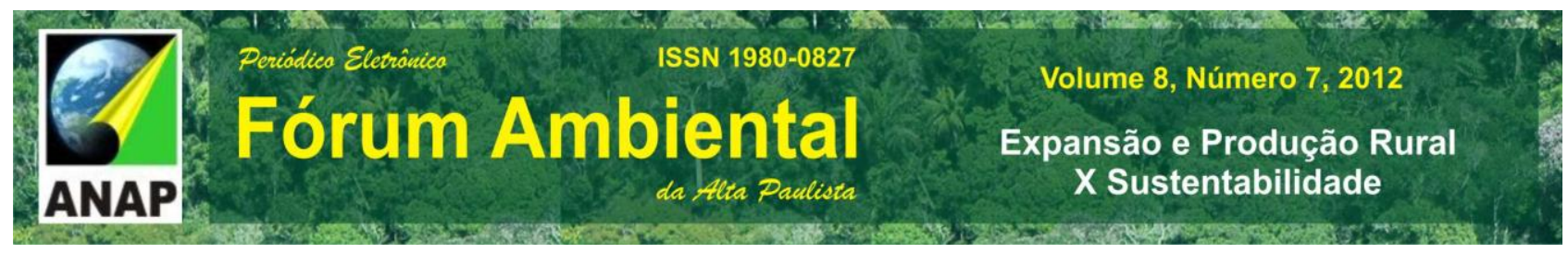

O eucalipto ocupa a $4^{a}$ posição em área cultivada no Brasil. Este fato faz com que se coloque em risco a soberania alimentar. Pois, ele tem substituído a produção de produtos de primeira necessidade como arroz e feijão.

O Brasil tem um total de 850 milhões de hectares de terras cultiváveis, apenas 70 milhões de hectares estão sendo usados para a produção. Destes, 21,5 milhões são de soja, 15 milhões de milho, 8 milhões de cana de açúcar e 7 milhões de eucalipto. E mais: desde 1992 não cresce a produção de arroz, feijão e mandioca no País, o que faz crescer a importação desses produtos de primeira necessidade. (OLIVEIRA apud ALMEIDA, 2010).

De acordo com o Defensor Público do estado de São Paulo, Wagner Giron de la Torre, estes números contrariam a legislação vigente, pois "[...] os índices máximos tolerados pelos parâmetros de zoneamento agroflorestal traçados por normas expedidas pela OMS e por estudiosos no assunto, não suplanta a faixa de segurança de 5\% dos territórios agricultáveis em cada município". [2010?, p. 4].

No caso de Mato Grosso do Sul, pelo Quadro 01, podemos verificar que a produção de eucalipto cresceu $83 \%$, enquanto no Brasil cresceu apenas $10 \%$.

Quadro 01 - Crescimento do plantio (em ha) de eucalipto no BR e no MS (2005-2007)

\begin{tabular}{|l|l|l|l|}
\hline Eucalipto & 2005 & 2007 & $\%$ \\
\hline Brasil & 3.407 .204 & 3.751 .867 & $10,1 \%$ \\
\hline MS & 113.432 & 207.687 & $83,1 \%$ \\
\hline
\end{tabular}

Fonte: ABRAF apud ALMEIDA, Rosemeire A. de. (2010).

Como podemos observar na Figura 01, que demonstra a territorialização do complexo celulose-papel no Brasil, atualmente, $21,2 \%$ da produção de celulose se concentra na região leste do estado de Mato Grosso do Sul. Esta região é composta por 17 municípios. A sua localização permite o plantio do eucalipto próximo à indústria de transformação em celulose e possibilita escoar a produção por meio de uma logística trimodal: rodovia-ferrovia-hidrovia. Nesta região, de acordo com Rosemeire A. de Almeida (2010), impera o modelo de sustentação que possibilita a efetivação do complexo de celulose-papel: isenção fiscal; expansão territorial; pouco uso de mão de obra (fruto da mecanização no plantio e no corte do eucalipto) e exportação. A expansão deste complexo de celulose-papel ocorre sob o controle da FIBRIA desde 2006, período em que adquiriu, por meio da troca de ativos com a International Paper, 90 mil ha plantados com eucalipto e 30 mil arrendados. 


\section{sem

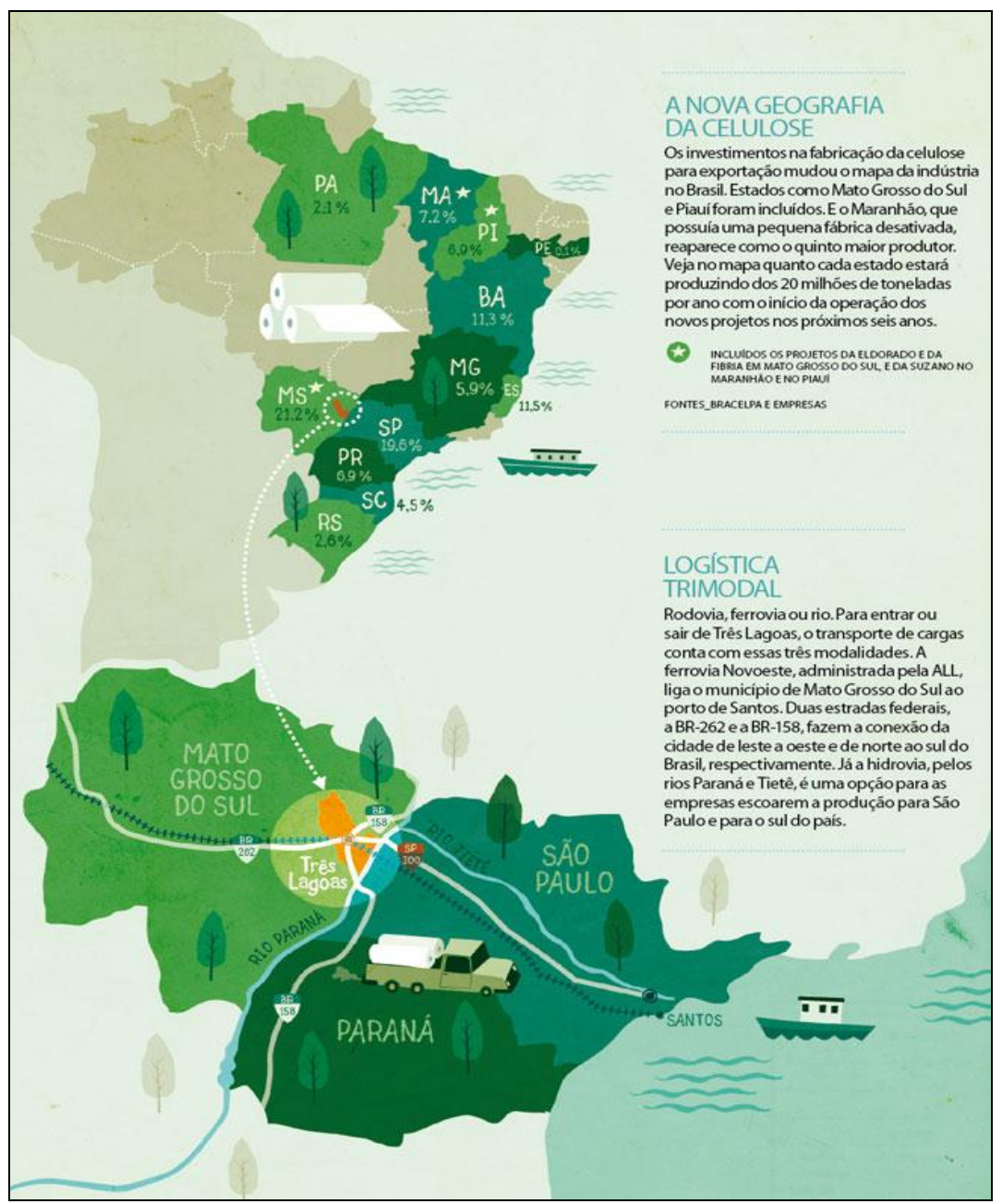

Figura 01- A territorialização da Celulose no Brasil e no Leste de MS Fonte: <http://epocanegocios.globo.com/Revista/Common/>

Como já havíamos discutido sobre o agrohidronegócio, além da questão logística, não podemos esquecer-nos das condições edáfico-climáticas que determinadas culturas exigem como água, solo e clima que são essenciais para a territorialização do eucalipto. Podemos notar pela Figura 01, que na região Leste de Mato Grosso do Sul, localiza-se a bacia rio Paraná, uma das "caixas d'água" do Brasil e, portanto, há presença de água em abundância. Este é um recurso natural indispensável à sustentação desse complexo celulose-papel que utiliza em média $57 \mathrm{~m}^{3}$ de água para produzir uma tonelada de pasta celulósica (SCHLESINGER, 2008; ALMEIDA, 2010).

A territorialização do agronegócio ocorre no cerrado facilitado pela topografia plana e abundância hídrica. Carlos Walter Porto-Gonçalves alerta acerca dos problemas 
ocasionados pela territorialização da monocultura e do latifúndio sobre o Cerrado que tem destruído a diversidade biofísica e cultural nestes lugares.

O cerrado brasileiro, com sua enorme diversidade biológica e cultural, vem se transformando, assim, numa área de expansão de grandes latifúndios produtivos, pelas enormes vantagens que oferece, seja pela riqueza hídrica que abriga, seja pela topografia plana de suas chapadas e de seus chapadões. Avaliase hoje que $70 \%$ da área das chapadas já esteja ocupada por esse tipo de empresa, seja com cultivo de grãos, algodão ou de monoculturas de plantação de madeira (eucaliptos e pinnus alba e pinnus elliotis).[...] Por sua vez, esse modelo transfere para a sociedade como um todo [...] seus danos ambientais diversos (PORTO-GONÇALVES, 2004, p. 223, grifo do autor).

De acordo com Mieceslau Kudlavicz (2011), apesar dos empresários do setor do complexo de celulose-papel negar que o plantio de eucalipto altere o balanço hídrico local, em trabalho de campo o autor pode comprovar o contrário ao conversar com camponeses que moram há muitos anos nos locais atingidos pelos impactos do plantio do eucalipto. Eles lhe disseram que após o cultivo do eucalipto ocorreu o desaparecimento de nascentes, açudes e lagoas na Microrregião de Três Lagoas. Em uma saída de campo, em agosto de 2010, um morador nascido e criado na região há 40 anos, apontou algumas nascentes que secaram durante este período. Segundo Wagner Giron de la Torre [2010?], ocorre o esgotamento de poços, minas d'água e demais corpos hídricos em função do enorme poder de sucção do eucalipto. Este fato é responsável pelo êxodo de agricultores afligidos com o ressecamento de suas fontes de água. Alguns estudos indicam que esse processo ocorreu com a territorilização do eucalipto no Sul da Bahia e norte de Minas onde secaram mais de 4 mil nascentes do Rio São Francisco.

Outro indicador de impactos ambientais profundos provocados pela expansão do eucalipto diz respeito à mudança de comportamentos na fauna regional. Veja o que escreve Mieceslau Kudlavicz sobre o assunto:

Um dos indicadores mais visíveis do desequilíbrio ambiental proveniente dos desmatamentos para implantação de pastagens e, mais recentemente, para plantio de eucalipto, é a presença de aves na cidade. [...] Ultimamente as aves estão invadindo os pomares dos camponeses e se alimentando de todas as frutas, inclusive de limão quando não encontram outro alimento. Esse fenômeno também se repete nos perímetros urbanos de outras cidades da região Leste do Estado. (2011, p.150). 
Processo semelhante ocorreu no sul da Bahia. O biólogo Elbano Paschoal diz que não há conectividade entre as pequenas ilhas preservadas e o mar de eucalipto. Os animais não utilizam o mar de monocultura para se locomover. Em suas palavras:

O desprezo e crueldade dispensados à fauna silvestre pelos promotores da monocultura de eucalipto, utilizando totalmente tabuleiros e terras planas, deixando apenas alguns grotões (ilhas de áreas íngremes) para "refúgio" da fauna silvestre são estarrecedores. Muitas espécies não vivem (não estão adaptadas) em áreas com relevo acidentado, e estão sendo localmente extintas, especialmente as espécies endêmicas e raras. Além do mais, não há conectividade entre as ilhas de vegetação (nativa) imersas no mar de eucalipto. $O$ eucaliptal não representa um corredor ecológico pleno, pois sabemos nós, ambientalistas, cientistas, empresários, técnicos do governo, etc., que inúmeras espécies não atravessam, muito menos utilizam o eucaliptal. Algumas espécies, mesmo as aves, cuja capacidade de deslocamento é maior que a de outras, sequer atravessam uma estrada aberta num ambiente natural. (apud TORRE, [2010?], p. 2-3).

Outra problemática que já discutimos relacionado ao agronegócio é o uso intensivo de agrotóxicos. No caso da monocultura do eucalipto, os herbicidas são utilizados para extrair as ervas daninhas que possam competir com as mudas de eucalipto. Este produto está provocando a morte de animais e árvores na região de Três Lagoas. Entre as árvores, se destaca o pequizeiro, nativa do cerrado e protegida por lei. Inclusive, há uma denúncia por parte dos moradores locais de que houve pulverização aérea dos herbicidas em 2010, até mesmo próximo a um assentamento (Assentamento Pontal do Faia, no município de Três Lagoas), prejudicando a produção e a saúde dos moradores. Este fato é negado pelos representantes da empresa FIBRIA, pois sabem que estão desrespeitando as leis ambientais (KUDLAVICZ, 2011).

Wagner Giron de la Torre explica que além dos produtos químicos utilizados para a fabricação do papel, o agronegócio da celulose-papel utiliza pesticidas a base de Glifosato, componente presente no herbicida Round'up da Monsanto, que elimina formigas e outros agentes prejudiciais ao desenvolvimento das mudas de eucalipto. Dito de outra maneira:

Afora o intenso processo químico historicamente utilizado na produção industrial do papel, as empresas fomentadoras desses cultivos - seja em terras próprias ou arrendadas - necessitam infestar o solo destinado à instalação da monocultura do eucalipto com toneladas e toneladas de pesticidas à base de glifosato (dentre outras tantas pestilências químicas), geralmente manejado com a aplicação do conhecido herbicida Round'up, da Monsanto, a fim de eliminar a presença de formigas e outros elementos naturais potencialmente nocivos ao esperado 
desenvolvimento das clonadas mudinhas, em processo tecnicamente conhecido como capina química. ([2010?, p. 5, grifo nosso).

As mudas concebidas em laboratório não sofrem com o efeito deste pesticida, "Mas a natureza não passa incólume a tanta desgraça!". (TORRES, [2010?], p. 5). Com a ação ventos e das chuvas grande parte das toneladas de materiais químicos utilizados no manejo da monocultura do eucalipto atinge as nascentes, cursos d'água, córregos, rios, contaminando pessoas, animais, pastagens etc. (TORRES, [2010?], p.5). Estudos feitos em laboratório concluem que os efeitos da contaminação por Glifosato são diversos, entre eles, o câncer. Dessa maneira,

Embora a comercialização de herbicidas à base de glyphosate seja liberada, estudos laboratoriais detectaram efeitos adversos em todas as categorias de testes toxicológicos. Entre estes incluem-se toxicidade a médio prazo (lesões em glândulas salivares), toxicidade a longo prazo (inflamações nas mucosas do estômago), danos genéticos (em células sanguíneas do corpo humano), efeitos reprodutivos (redução dos espermatozóides em ratos; maior frequência de espermatozóides anormais em coelhos), e carcinogenicidade (maior frequência de tumores no fígado de ratos e câncer de tiróide em ratas).(COX, 1998, p. 1).

O desrespeito às leis ambientais é enorme. Como afirma Wagner Giron de la Torre essas empresas "[...] não respeitam norma ambiental alguma, investem sobre cumes de morros, violam áreas de nascentes, irrompem em várzeas e aniquilam matas ciliares, intoxicando cursos d'água, rios e provocando a morte de incontáveis espécies da fauna local". (TORRES, [2010?], p.5). Uma atitude de desrespeito às leis ambientais vigentes foi descoberta pela Polícia Militar Ambiental de Três Lagoas que flagrou um carro da empresa FIBRIA captando água próxima a uma nascente em uma fazenda. Foi aplicada uma multa de $\mathrm{R} \$ 20.000,00$ à empresa, pois não possuía autorização e nem licença ambiental para realizar esta atividade (KUDLAVICZ, 2011).

Esses impactos socioambientais provocados pela expansão do eucalipto na região leste de Mato Grosso do Sul tem atingido os Projetos de Assentamento da Microrregião de Três Lagoas. Um exemplo é o Projeto de Assentamento Pontal do Faia, no município de Três Lagoas, cuja situação tende a se tornar mais grave, pois a construção da nova indústria de papel e celulose, conhecida como Projeto Eldorado da Florestal Investimentos Florestais S/A, está a pouco mais de um quilômetro do assentamento (KUDLAVICZ, 2011). E quanto ao Assentamento Alecrim, podemos ver 
na Foto 01 o monocultivo de eucalipto cercando o assentamento. Este fato coloca em risco a saúde e a produção dos camponeses-assentados.

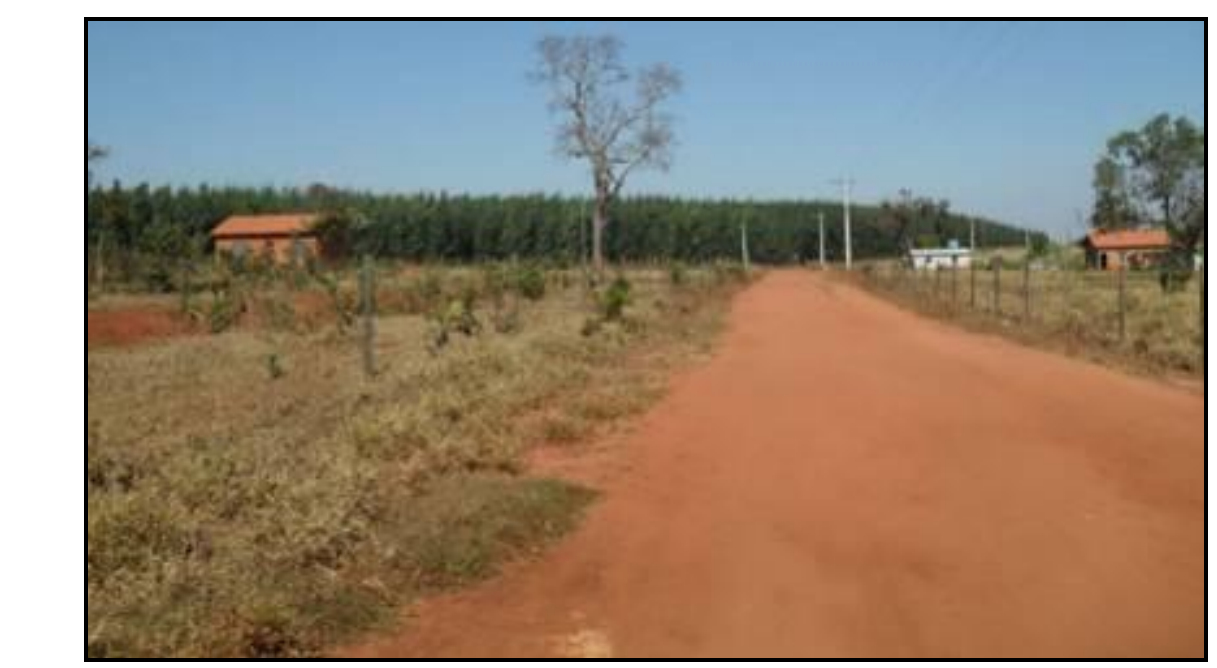

Foto 01 - Assentamento Alecrim cercado com Plantios de Eucalipto Fonte: KUDLAVICZ, Mieceslau (2010).

Com base nas informações transcritas até o momento é possível entender porque o modelo de latifúndio com monocultura de eucalipto é denominado por entidades ambientalistas de "Deserto Verde". Apesar da aparência de floreta, possui, na essência, uma reduzida biodiversidade (KUDLAVICZ, 2011). O que a FRIBIA denomina de "floresta" é cultivada com clones de eucalipto para gerar a madeira mais padronizada e adequada à produção de celulose. Como podemos observar na Foto 02, no pátio da FIBRIA existe um verdadeiro "mar de toras". São estocados 60 mil metros cúbicos de madeira proveniente da "floresta de eucaliptos". Se as toras fossem colocadas uma ao lado da outra, preencheriam 1,5 mil campos de futebol (SPOTORNO, 2010).

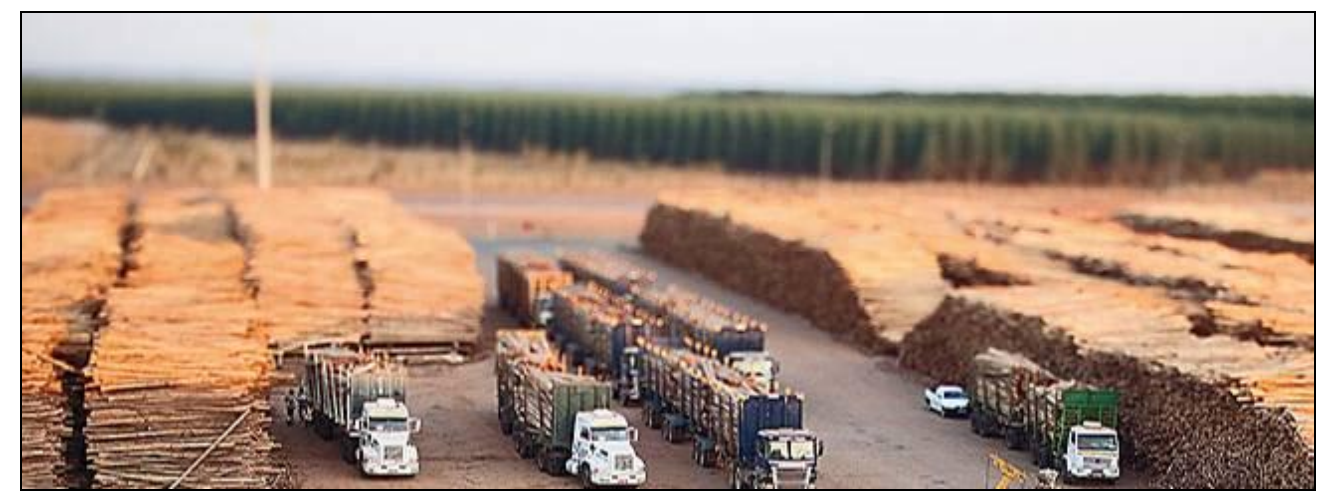

VIII Fórum Ambiental da Alta Paulista, v. 8, n. 7, 2012, p. 29-45. 


\section{Foto 02 - Mar de Toras de eucalipto}

Fonte: (Luiz Maximiano) <http://epocanegocios.globo.com/Revista/Common/>.

Toda a colheita é mecanizada, como podemos ver na Foto 03. No trabalho de campo, em setembro de 2010 na micro-região de Três Lagoas, observamos que esta máquina que faz a colheita é capaz de, em aproximadamente 1 minuto, cortar o eucalipto, descascar e empilhar. O resultado após a colheita é esta paisagem devastada, apenas com os restos dos troncos de eucaliptos que sobraram, como podemos visualizar na Foto 04.

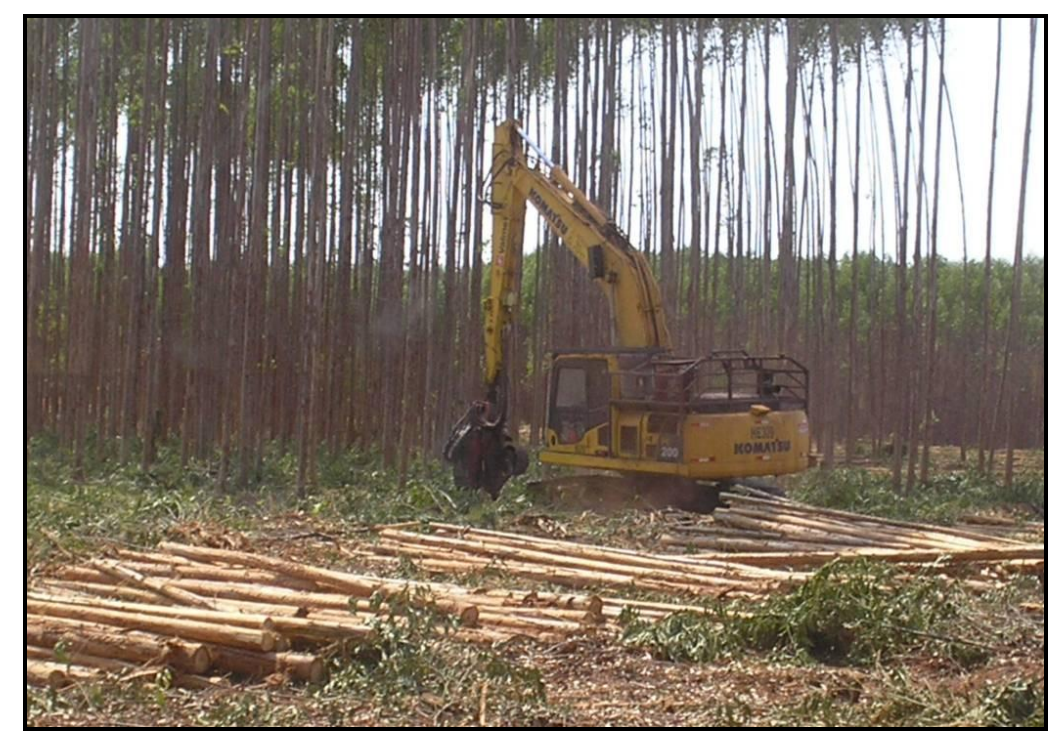

Foto 03 - Colheita mecanizada

Fonte: Trabalho de campo (set. 2010)

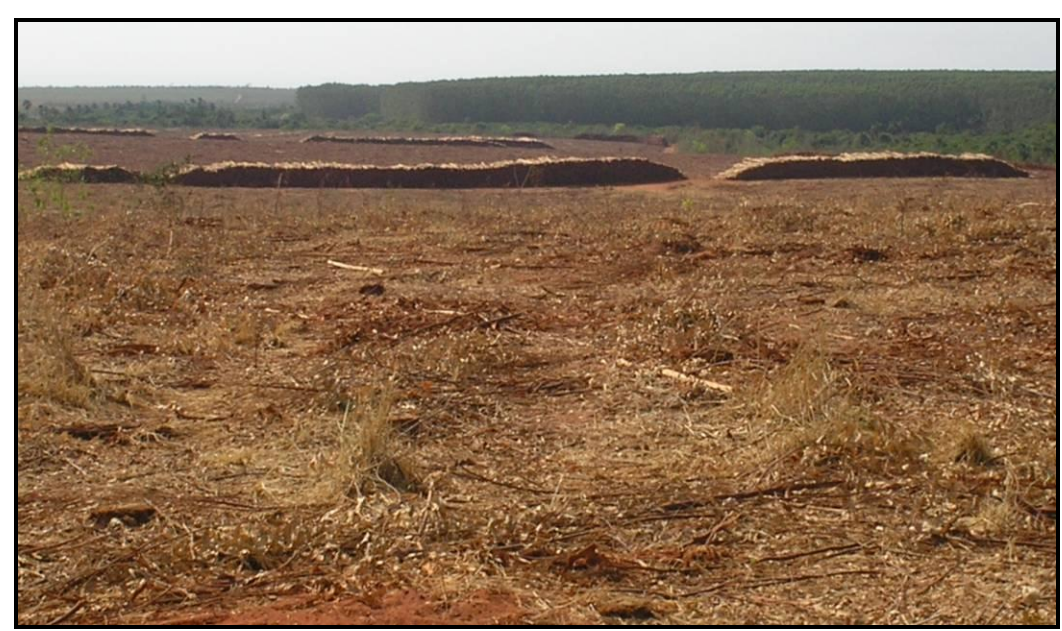

Foto 04 - Paisagem devastada após a colheita do eucalipto

Fonte: Trabalho de campo (set. 2010) 


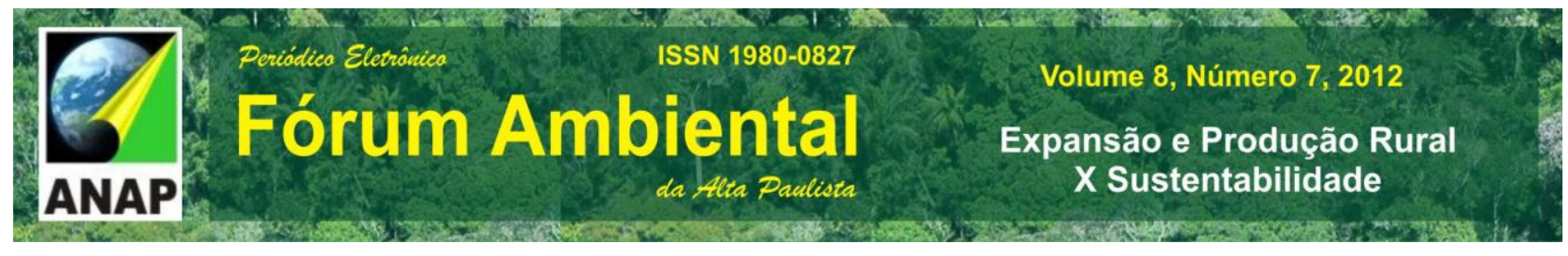

\section{CONSIDERAÇÕES FINAIS}

A combinação destrutiva do agronegócio no Brasil se dá pela relação entre as seguintes características: grandes extensões de terras, baixos salários pagos aos trabalhadores, monocultura e uso de agrotóxicos (STEDILE, 2006). Dessa forma, entendemos que essa combinação de latifúndio, exploração intensa da mão-de-obra, monocultura, agrotóxicos, mecanização, transgênicos e produção de commodities, mostra-se insustentável. Por isso, nossa opção teórica - política - ideológica é pela agricultura camponesa. Este modelo agrário-agrícola coloca em risco a soberania alimentar, destrói a diversidade natural e cultural (sociobiodiversidade), desterritorializa o campesinato gerando a miséria e a exclusão social. A expansão do eucalipto na região leste de Mato Grosso do Sul é mais uma expressão desse modelo agrário-agrícola denominado de complexo celulose-papel que demonstra a insustentabilidade social e ambiental do agronegócio.

\section{REFERÊNCIAS BIBLIOGRÁFICAS}

ALMEIDA, Rosemeire Aparecida de (Org.). Pequeno glossário da questão agrária. Três Lagoas, 2004. Mimeografado.

ALMEIDA, Rosemeire Aparecida de. A formação do vale da celulose: desdobramentos socioterritoriais do plantio de eucalipto na região Leste de Mato Grosso do Sul. Três Lagoas: UFMS, 2010. (não publicado).

CAMACHO, Rodrigo Simão. O ensino da geografia e a questão agrária nas séries iniciais do ensino fundamental. 2008. 462 f. Dissertação (Mestrado em Geografia) Universidade Federal de Mato Grosso do Sul, Aquidauana, 2008.

CAPORAL, Francisco Roberto. Em defesa de um plano nacional de transição agroecológica: compromisso com as atuais e nosso legado para as futuras gerações. In: SAUER, Sérgio e BALESTRO, Moisés V. (orgs.). Agroecologia e os desafios da transição agroecológica. São Paulo: Expressão Popular, 2009.

COELHO, Maria Célia Nunes. Impactos Ambientais em Áreas Urbanas - Teorias, Conceitos e Métodos de Pesquisa. In: GUERRA, Antonio J. Teixeira, Cunha, Sandra Baptista da. (Orgs.). Impactos Urbanos no Brasil. Rio de Janeiro: Bertrand Brasil, 2001. 
COX, Caroline. Glyphosate (Round Up). Tradução: Nicoleta T.N. Sabetzki. Journal of Pesticide Reform/Fall, Estação Experimental de Itajaí-Epagri, vol. 18, n. 3, 1998.

FERNANDES, Bernardo Mançano. Entrando nos territórios do Território. In: PAULINO, Eliane T.; FABRINI, João E. (Org.). Campesinato e territórios em disputa. São Paulo: Expressão Popular, 2008.

KUDLAVICZ, Mieceslau. Dinâmica agrária e a territorialização do complexo celulose/papel na microrregião de Três Lagoas/MS. 2011. Dissertação (Mestrado em Geografia) - Universidade Federal de Mato Grosso do Sul, Três Lagoas, 2011.

OLIVEIRA, Ariovaldo U. de. Barbárie e modernidade: as transformações no campo e o agronegócio no Brasil. Revista Terra Livre, São Paulo: AGB, ano 19, v. 2, n. 21, p. 113156, jul./dez. 2003.

PORTO-GONÇALVES, Carlos Walter. Geografia da riqueza, fome e meio ambiente: pequena contribuição crítica ao atual modelo agrário/agrícola de uso dos recursos naturais. In: OLIVEIRA, Ariovaldo U. de; MARQUES, Marta Inês Medeiros (Org.). 0 campo no século XXI: território de vida, de luta e de construção da justiça social. São Paulo: Casa amarela; Paz e Terra, 2004. p.27-64.

SCHLESINGER, Sérgio. Lenha nova para a velha fornalha. Rio de Janeiro: FASE, 2008.

SPOTORNO, Karla. Três Lagoas: Capital mundial da celulose. Disponível em: <http://epocanegocios.globo.com/Revista/Common/>. Acesso em: 20 nov. 2010.

STEDILE, João Pedro. A sociedade deve decidir o modelo agrícola para o país. Revista Caros Amigos, São Paulo: Casa Amarela, ano 10, n.109, p. 17, abr. 2006.

THOMAZ JUNIOR, Antonio. O agrohidronegócio no centro das disputas territoriais e de classe no Brasil do século XXI. Campo-território: revista de geografia agrária, v.5, n.10, p. 92-122, ago. 2010.

TORRE, Wagner Giron de la. Eucalipto: o verde enganador. Reflexões sobre o avanço irrefreado da monocultura do eucalipto e os imensuráveis impactos ambientais e sociais dele defluentes. [S.L: s.n], [2010?]. Digitado. 